\title{
Prevalence of hypodontia of permanent dentition in a sample of orthodontic patients In Erbil City: An orthopantomograph study
}

Received: 4/ 5/ 2016

Accepted: 18/9/2016

\begin{abstract}
Rebin Ali Mohammed Amin*
Omar Fawzi Abduljabbar*

Muhammad Husain Saleh *

Abstract

Background and objective: Developmentally missing teeth include hypodontia, oligodontia, and anodontia. In the case of absence of one or more teeth or supernumerary one, the need for treatment is very great. Aesthetic concerns, periodontal diseases and malocclusion are some of the complications following hypodontia. This study aimed to find out the prevalence and distribution of hypodontia in Erbil orthodontic patients in relation to the side, jaw, tooth types and gender.

Methods: Orthopantomograms of 600 patients (10-34 years old), seeking orthodontic treatment from different orthodontic clinics in Erbil city between 2014 and 2015 were evaluated. A tooth diagnosed as congenitally missing when cannot be identified or discerned radiographically on the basis of calcification and there is no evidence of extraction.

Results: The prevalence of hypodontia was $6.66 \%$. Maxillary lateral incisors were most frequently missing $(42.68 \%)$, followed by mandibular second premolars $(19.51 \%)$. Hypodontia was more frequently found in females with no statistically significant difference. $62.5 \%$ of hypodontia located in maxilla while $27.5 \%$ located in the mandible and only $10 \%$ was in both arches in the same patient.

Conclusion: The pattern and prevalence of hypodontia are different among races and ethnic groups. The prevalence of hypodontia in Erbil orthodontic patients was 6.6\%. Upper lateral incisor was the most frequently missing teeth. Tooth agenesis in the upper arch was more prevalent than in the lower arch.
\end{abstract}

Keywords: Hypodontia; Supernumerary; Orthopantomograph.

\section{Introduction}

Dental anomalies including variation in the size, form, position and number of teeth are one of the anomalies of the human structure that result from certain genes and some etiological events in the prenatal and postnatal periods. ${ }^{1}$ Developmentally missing teeth include hypodontia (absence of one to six teeth), oligodontia (absence of more than six teeth), and anodontia (complete absence of teeth). ${ }^{2}$ In case of absence of one or more teeth or supernumerary one, the need for treatment is very great according to the Index of Orthodontic Treatment Need. ${ }^{3}$ The prevalence of hypodontia varies from $0.03 \%$ to $10.1 \%$ in different populations. ${ }^{4}$ As a general rule, if only a few teeth are missing, the absent tooth would be the most distal tooth of any given type. ${ }^{5}$ Aesthetic concerns, periodontal diseases and malocclusion are some of the complications following hypodontia. Some studies reported that hypodontia in the anterior region has a significant effect on skeletal relationships. ${ }^{6}$ However, each of these problems can be an indication for orthodontic treatment. For example, missing maxillary lateral incisor impairs dental aesthetics and function from a very young age. ${ }^{7}$ Therefore, investigating the prevalence of hypodontiais of significant clinical value, in terms of early diagnosis and effective treatment planning. ${ }^{8,9}$ This is very important in preventing complications of hypodontia, including periodontal

* Department of P.O.P, College of Dentistry, Hawler Medical University, Erbil, I raq. 
diseases, malocclusion and lack of alveolar growth. ${ }^{10-12}$ The differences in prevalence may be due to variation in samples with respect to measuring techniques, different methods of radiography and clinical examinations, age, gender, geographic or demographic profiles. ${ }^{11,13-15}$ The aim of the study was to find out the prevalence and distribution of hypodontia in Erbil orthodontic patients in relation to the site, jaw, tooth types, and gender.

\section{Methods}

In this cross-sectional study, orthopantomograms of 600 patients seeking orthodontic treatment from different Orthodontic Clinics in Erbil city between 2014 and 2015 were evaluated. Detailed medical, dental and family histories were obtained for all subjects. The patient's inclusion criteria were as follows:

1. No significant medical history, such as significant trauma to the jaw bones.

2. No history of metabolic disorders or syndrome affecting bone metabolism and/ or tooth formation.

3. No history of extraction or previous orthodontic treatment.

4. No cleft lip and/or palate, craniofacial anomalies and diagnosed syndromes.

The age of patients was between (10-34) years old at the time the OPGs taken before initiation of orthodontic treatment. A tooth diagnosed as congenitally missing when cannot be identified or discerned radio graphically on the basis of calcification and there is no evidence of extraction. If an accurate diagnosis of hypodontia cannot be made, the file excluded. The overall prevalence of hypodontia dentition (excluding missing third molars), as well as its pattern of occurrence regarding the involved sides (left vs. right / anterior vs. posterior), tooth types, and gender investigated twice by two orthodontists. Statistical analysis: The Chi-square test performed to determine the significance of the difference for upper and lower numerical teeth abnormalities and the difference between males and females. The level of significance was set at $5 \%$.

\section{Results}

A total of 600 patients were reviewed and examined. Of these, 239 were males $(39.83 \%)$ and 361 were females $(60.17 \%)$. Hypodontia was found in 40 patients (28 females and 12 males). The prevalence of hypodontia was $6.66 \%$. The prevalence was $5.02 \%$ in males and $7.75 \%$ in females $(P=0.25)$ as shown in Table 1.

Table 1: Distribution of subject and prevalence of hypodontia.

Gender

$\mathbf{N}$

Prevalence

No.

28

12

5.02
40
Total

600

Male

$$
239
$$

00

\section{$P$ value}

$\%$

7.75 
In these 40 patients, a total of 82 permanent teeth were missing (24 teeth in males and 58 teeth in females). The distribution of hypodontia by gender is shown in Table 2. Thirty percent of the orthodontic patients had hypodontia of one tooth while $57.5 \%$ had hypodontia of two teeth and $5 \%$ had three teeth missing, and just $2.5 \%$ had four teeth missing. No significant association was detected between gender and hypodontia $(P=0.12)$.
Maxillary lateral incisors were most frequently missing $(68.62 \%)$ with a significant difference with other teeth, followed by mandibular second premolars $(51.61 \%)$ and mandibular central incisor $(25.8 \%)$, maxillary second premolars $(23.52 \%)$, followed, in order, by the maxillary first premolar $(9.67 \%)$. On the other hand, maxillary and mandibular second molars and canines were never absent (Table 3).

Table 2: Distribution of the number of missing teeth by gender.

\begin{tabular}{lccccccc}
\hline \multirow{2}{*}{$\begin{array}{l}\text { Number of } \\
\text { missing teeth }\end{array}$} & \multicolumn{2}{c}{ Female } & \multicolumn{2}{c}{ Male } & \multicolumn{2}{c}{ Total } & P value \\
\hline 1 & No. & $\%$ & No. & $\%$ & No. & $\%$ & \\
2 & 10 & 35.71 & 2 & 16.66 & 12 & 30 & \\
3 & 15 & 53.57 & 8 & 66.66 & 23 & 57.5 & \\
4 & 0 & 0 & 2 & 16.66 & 2 & 5 & 0.12 \\
6 & 1 & 3.57 & 0 & 0 & 1 & 2.5 & \\
9 & 1 & 3.57 & 0 & 0 & 1 & 2.5 & \\
Total & 1 & 3.57 & 0 & 0 & 1 & 2.5 & \\
\hline
\end{tabular}

Table 3: Distribution of congenitally missing permanent teeth in the maxillary and mandibular arches.

\begin{tabular}{lccccccc}
\hline \multirow{2}{*}{ Tooth } & \multicolumn{2}{c}{ Upper } & \multicolumn{2}{c}{ Lower } & \multicolumn{2}{c}{ Total } & $P$ value \\
& No & $\%$ & No & $\%$ & No. & $\%$ & \\
\hline Central Incisor & 0 & 0 & 8 & 25.8 & 8 & 9.75 & \\
Lateral Incisor & 35 & 68.62 & 2 & 6.45 & 37 & 45.12 & \\
Canine & 0 & 0 & 0 & 0 & 0 & 0 & \\
$1^{\text {st }}$ Premolar & 4 & 7.84 & 3 & 9.67 & 7 & 8.53 & 0.10 \\
$2^{\text {nd }}$ Premolar & 12 & 23.52 & 16 & 51.61 & 28 & 34.14 & \\
$1^{\text {st }}$ Molar & 0 & 0 & 2 & 6.45 & 2 & 2.43 & \\
$2^{\text {nd }}$ Molar & 0 & 0 & 0 & 0 & 0 & 0 & \\
Total & 51 & 100 & 31 & 100 & 82 & 100 & \\
\hline
\end{tabular}


Within the 82 congenital missing teeth registered, symmetrical hypodontia was predominant. Bilateral or contralateral hypodontia (e.g., maxillary first premolar right and left) accounted for 28 pairs representing $70 \%$ of all congenital missing teeth, and the remaining 12congenital missing teeth were located unilaterally $(30 \%)$. Moreover, hypodontia was more frequent in the left side $(54.87 \%)$ than in the right side $(45.13 \%)$ of the maxillary and mandibular arches (Table 4). No significant differences were detected between males and females regarding the side of hypodontia. The absence of maxillary lateral incisors in females $(4.16 \%)$ were more common than males $(1.5 \%)$ and were more common in left side than in right side, and were more bilateral (25.49\%) than unilateral (17.64\%). $62.2 \%$ of hypodontia located in maxilla while $37.8 \%$ located in mandible with no significant difference between males and females regarding the jaw affected by hypodontia $(P=0.22)$ as shown in Table 5.

\section{Discussion}

The results of this study showed a prevalence of $6.6 \%$ of hypodontia in orthodontic patients. This finding is less than the prevalence of hypodontia in Australian orthodontic patients $(8.1 \%){ }^{16}$ Japanese orthodontic patients $(8.5 \%),{ }^{17}$ Lithuanian orthodontic patients $(8 \%)$ by, ${ }^{18}$ Iranian orthodontic patients $(9.1 \%) .{ }^{19}$ While the prevalence in Mexican orthodontic patients was $2.7 \%{ }^{8}$ and Venezuela $(4 \%)^{20}$ which are lower than the prevalence observed in the present study. This finding is near to prevalence of study done in Brazil by Raquel Ribeiro Gomes which is $6.3 \% .^{21}$ The prevalence of hypodontia in orthodontic patients differs in different ethnic groups and regions in the world. Excluding the third molar, hypodontia ranges from $2.6 \%$ in Turkey $^{22}$ to $5.5 \%$ in Mexico, ${ }^{8} 6.3 \%$ in Brazil, ${ }^{21} 8.5 \%$ in Japan, ${ }^{17}$ $11.1 \%$ in Korea, ${ }^{12} 14.7 \%$ in Hungary ${ }^{23}$ to $26.4 \%$ in Thais. $^{24}$ The great range of prevalence for hypodontia observed in different population may be due to

Table 4: Distribution of hypodontia between genders by the side.

\begin{tabular}{lccccccc}
\hline \multirow{2}{*}{ Teeth } & \multicolumn{2}{c}{ Male } & \multicolumn{2}{c}{ Female } & \multicolumn{2}{c}{ Total } & \multirow{2}{*}{ Nalue } \\
& No. & $\%$ & No. & $\%$ & No. & $\%$ & \\
\hline Right & 13 & 54.16 & 24 & 41.37 & 37 & 45.13 & \\
Left & 11 & 45.84 & 34 & 58.63 & 45 & 54.87 & 0.41 \\
Total & 24 & 100 & 58 & 100 & 82 & 100 & \\
\hline
\end{tabular}

Table 5: Distribution of hypodontia between genders by the jaw.

\begin{tabular}{lccccccc}
\hline Teeth & \multicolumn{2}{c}{ Male } & \multicolumn{2}{c}{ Female } & \multicolumn{2}{c}{ Total } & P value \\
& No. & $\%$ & No. & $\%$ & No. & $\%$ & \\
\hline Maxilla & 12 & 50 & 39 & 67.3 & 51 & 62.2 & \\
Mandible & 12 & 50 & 19 & 32.7 & 31 & 37.8 & 0.22 \\
Total & 24 & 100 & 58 & 100 & 82 & 100 & \\
\hline
\end{tabular}


geographic differences. ${ }^{25,26}$ Hypodontia was more frequently found in females with no statistical difference, and this is agreeing with several studies, ${ }^{13,16-18,20,21,27}$ while Bäckman and Wahlin found significant difference between genders. ${ }^{28}$ The higher prevalence of hypodontia in females may be due to biological differences and higher demands to aesthetic by females that make more orthodontic treatment need. However, several investigations found higher prevalence in males ${ }^{11,29}$ and some reported no difference between gender. ${ }^{12}$ In this study, the most frequent congenitally missing teeth were the upper lateral incisors followed by lower second premolar, upper second premolars, subsequently followed by the lower central incisors. On the other hand, the least tooth to be found missing were the upper first premolar. This study is in accordance with several other studies. $8,11,12,19,21-23,27,30$ There is variation among different nations and countries about the most common missing tooth, excluding third molars. According to some research, the mandibular second premolar is the most common missing tooth. $4,13,16,17,28,31$ Also, the nationality of patients seeking orthodontic treatment may reflect different psycho-social aspects between regions. Also, in countries where smile aesthetics are more attended, missing of lateral incisor hypodontia may motivate parents and patients to seek orthodontic treatment. ${ }^{21}$ The location of missing teeth differs in different studies. In some studies, it was more in maxilla than mandible that is consistent with most of the previous studies. ${ }^{6,19}$ However, there are studies which had found a greater missing rate in the mandible. ${ }^{11,12,19,20,31}$ In majority studies the distribution of missing teeth between the right and left sides was the same. ${ }^{11}$ In this study, teeth were missing more often on the left which is in accordance with Farhat, ${ }^{31}$ whereas Fekonja observed more prevalence of missing teeth in the right side. ${ }^{27} \mathrm{We}$ found the majority of patients had one or two teeth missing which agree with two other studies. ${ }^{11,31}$ Because hypodontia is the most common anomaly in the development of the human dentition, many studies have been conducted on the prevalence of hypodontia in different nations and countries. The patients' age may affect the results. Calcification of some teeth may begin after the age of 9 or 10 years. ${ }^{13}$ Therefore, the decision for missing teeth before age 10 gives an unreliable result. Also due to delayed development of premolars, findings of most frequently missing teeth can also affect the result, and it may be a reason for the higher prevalence of maxillary lateral incisor missing in some studies. $8111,12,19,21-23,27,30$ Also, the missing teeth were more often absent bilaterally. Goya et al., Endo et al., Medina, Sisman et al. and Silva Meza also reported that missing teeth are mostly found bilaterally. $8,11,14,17,20$

\section{Conclusion}

The pattern and prevalence of hypodontia are different among races and ethnic groups. The prevalence of hypodontia in Erbil orthodontic patients was near to Brazil. The upper lateral incisor was the most frequently missing teeth, followed by the mandibular second premolars. Tooth agenesis in the upper arch was more prevalent than in the lower arch.

\section{Conflicts of interest}

The authors report no conflicts of interest.

\section{References}

1. Karadas M, Celikoglu M, Akdag MS, Evaluation of tooth number anomalies in asubpopulation of the North-East of Turkey. Eur J Dent 2014: 8(3); 337-41.

2. Arte S. Phenotypic and genotypic features of familial hypodontia, PhDThesis, Institute of Dentistry, University of Helsinki, Finland; 2001.

3. Helton AT, Hobson RS, Slater D. A preliminary evaluation of pre-treatment hypodontia patients using the Dental Aesthetic Index. How does it compare with other commonly used indices? Eur J Orthod2008; 30: 244-8.

4. Mattheeuws N, Dermaut L, Martens G. Has hypodontia increased in Caucasians during the $20^{\text {th }}$ century? A meta-analysis. Eur J Orthod 2004; 226:99-103. 
5. Amini F, Rakhshan V, Babaei P. Prevalence and pattern of hypodontia in the permanent dentition of 3374 Iranian orthodontic patients. Dent Res J 2012;9:245-50.

6. Acharya PN, Jones SP, Moles D, Gill D, Hunt NP. A cephalometric study to investigate the skeletal relationships in patients with increasing severity of hypodontia. Angle Orthod 2010; 80:511-8.

7. Kavadia S, Papadiochou S, Papadiochos I, Zafiriadis L. Agenesis of maxillary lateral incisors: A global overview of the clinical problem. Orthodontics (Chic) 2011; 12:296-317.

8. Silva Meza R. Radiographic assessment of congenitally missing teeth in orthodontic patients. Int J Pediatr Dent2003; 13:112-6.

9. Pemberton TJ, Das P, Patel PI. Hypodontia: Genetics and future perspectives. Braz J Oral Sci 2005; 4:695-709.

10. Kokich VG, Kokich VO. Congenitally missing mandibular second premolars: Clinical options. Am J Orthod Dentofacial Orthop 2006; 130:43744.

11. Sisman Y, Uysal T, Gelgor IE. Hypodontia, Does the Prevalence and Distribution Pattern Differ in Orthodontic Patients? Eur J Dent 2007; 1: 167-73.

12. Chung CJ, Han JH, Kim KH. The pattern and prevalence of hypodontia in Koreans. Oral Dis2008; 14:620-5.

13. Polder BJ, Van't Hof MA, Van der Linden FP, Kuijpers-Jagtman AM. A meta-analysis of the prevalence of dental agenesis of permanent teeth. Community Dent Oral Epidemiol 2004; 32:217-26.

14. Goya HA, Tanaka S, Maeda T, Akimoto Y. An orthopantomographic study of hypodontia in permanent teeth of Japanese pediatric patients. J Oral Sci 2008; 50:143-50.

15. De Coster PJ, Marks LA, Martens LC, Huysseune A. Dental agenesis: Genetic and clinical perspectives. J Oral Pathol Med 2009; 38:1-17.

16. Uslu O, Akcam MO, Evirgen S, Cebeci I. Prevalence of dental anomalies in various malocclusions. Am J Orthod Dentofacial Orthop 2009; 135(3):328-35.

17. Endo T, Ozoe R, Yoshino S, Shimooka S. Hypodontia patterns and variations in craniofacial morphology in Japanese orthodontic patients. Angle Orthod 2006; 76:996-1003.

18. Giedrè Trakinienè, Monika Ryliškytè, Aurelija Kiaušaitè. Prevalence of teeth number anomalies in orthodontic patient. SBDMJ 2013; 15: 47-53.

19. Vahid-Dastjerdi E, Borzabadi-Farahani A, Mahdian M, Amini N. Non-syndromic hypodontia in an Iranian orthodontic population. J Oral Sc 2010; 52(3):455-61.

20. Medina AC. Radiographic study of prevalence and distribution of hypodontia in a pediatric orthodontic population in Venezuela. Pediatr Dent
2012; 34(2):113-6.

21. Gomes RR, da Fonseca JA, Paula LM, Faber J, Acevedo AC. Prevalence of hypodontia in orthodontic patients in Brasilia, Brazil. Eur J Orthod 2010; 32:302-6.

22. Altug-Atac AT, Erdem D. Prevalence and distribution of dental anomalies in orthodontic patients. Am J Orthod Dentofacial Orthop 2007; 131:510-4.

23. Gabris K, Fabian G, Kaan M, Rozsa N, Tarjan I. Prevalence of hypodontia and hyperdontiain paedodonticand orthodontic patients in BUdapest. Community Dent Health 2006; 23:802.

24. Kositbowornchai S, Keinprasit Ch,Poomat N. Prevalence and distribution of dental anomalies in pretreatment orthodontic Thai patient. KDJ2010; 13 (2): 92-199.

25. Behr $M$, Proff $P$, Leitzmann $M$, Pretzel $M$, Handel G, Schmalz G, et al. Survey of congenitally missing teeth in orthodontic patients in Eastern Bavaria. Eur J Orthod 2011; 33:32-6.

26. Vani NV, Saleh SM, Tubaigy FM, Idris AM. Prevalence of developmental dental anomalies among adult population of Jazan, Saudi Arabia. SJDR 2016; 7(1): 29-33.

27. Fekonja A. Hypodontia in orthodontically treated children. Eur J Orthod 2005; 27:457-60.

28. Bäckman B, Wahlin $Y B$. Variations in number and morphology of permanent teeth in 7-year-old Swedish children. Int J Paediat Dent 2001; 11(1): 11-7.

29. Kapdan A, Kustarci A, Buldur B, Arslan D, Kapdan A. Dental anomalies in the primary dentition of Turkish children. Eur J Dent 2012; 6:178-83.

30. Gábris K, Fábián G, Kaán M, Rózsa N, Tarján I. Prevalence of hypodontia and hyperdontia in paedodontic and orthodontic patients in Budapest. Community Dent Health 2006; 23: 80-2.

31. Farhat A. Prevalence of hypodontia in orthodontic patients in a Pakistan samplea study. Pak Oral Dent J 2010; 30:142-5. 